\title{
Carbonylation of olefins by carbon monoxide and alcohols in the presence of Pd-complex catalytic system
}

\author{
Kairzhan Shalmagambetov, Nurbolat Kudaibergenov, Gulbanu Zhaksylykova, Perizat \\ Almatkyzy, Diana Mamyrkhan, Marat Bulybayev, Arkhat Esenov
}

Al-Farabi Kazakh National University, Almaty, Kazakhstan

\begin{abstract}
In order to develop new, efficient and environmentally friendly methods for the preparation of practically valuable esters of carboxylic acids, studies of the hydroalkoxycarbonylation reaction of a number of terminal olefins of normal structure (hexene-1, heptene-1, octene-1, nonene-1) with carbon monoxide and alcohols in presence of metal complex catalysts based on palladium phosphine complexes at low carbon monoxide pressures $(\leq 20 \mathrm{~atm})$. Two- and three-component systems based on $\mathrm{PdCl}_{2}$ and $\mathrm{Pd}(\mathrm{Acac})_{2}, \mathrm{PdCl}_{2}\left(\mathrm{PPh}_{3}\right)_{2}, \mathrm{Pd}\left(\mathrm{PPh}_{3}\right)_{4}$ complexes containing a free ligand $\left(\mathrm{PPh}_{3}\right)$ as a stabilizer and Bronsted acid $(\mathrm{TsOH})$ as a promoter were studied as catalysts. It was shown that only the three-component systems $\mathrm{PdCl}_{2}-\mathrm{PPh}_{3}-\mathrm{TsOH}, \quad \mathrm{PdCl}_{2}\left(\mathrm{PPh}_{3}\right)_{2}-\mathrm{PPh}_{3}-\mathrm{TsOH}, \quad \mathrm{Pd}(\mathrm{Acac})_{2}-\mathrm{PPh}_{3}-$ $\mathrm{TsOH}$, and $\mathrm{Pd}\left(\mathrm{PPh}_{3}\right)_{2}-\mathrm{PPh}_{3}-\mathrm{TsOH}$ have the highest catalytic activity in the studied reactions. It was found that the reaction of hydroalkoxycarbonylation of $\alpha$-olefins proceeds with the formation of a mixture of linear and branched products. The influence of various conditions of the reaction (the ratio of the initial reagents and the components of the catalytic systems, temperature, $\mathrm{CO}$ pressure, duration) on the course of the process and on the yield of the target products was investigated. The optimal parameters of the studied reactions have been found.
\end{abstract}

\section{Introduction}

A careful analysis of the achievements of catalytic chemical synthesis in recent years makes it possible to assert with great confidence that the future of laboratory and industrial organic synthesis will largely be determined by the success of the development of homogeneous catalysis, more precisely, by the success in the development of homogeneous metal complex catalysts. Great hopes are pinned on the latter in solving important problems related to saving raw materials and energy in the implementation of industrial processes of organic synthesis [1-4]. The beginning of the emergence of industrial processes using homogeneous metal complex catalysis can be considered the work of O. Rehlen (1938) on the synthesis of aldehydes by the interaction of alkenes with synthesis gas in the presence of cobalt carbonyls as a catalyst. Around the same time, this industrially important reaction of homogeneous catalysis (carbonylation of organic substrates with carbon monoxide) was 
developed in the works of V. Reppe in the late thirties and early forties of the last century. The Reppe synthesis includes a wide variety of carbonylation reactions of unsaturated compounds (alkenes, alkynes) or compounds with an active $\mathrm{C}-\mathrm{X}$ bond ( $\mathrm{X}=\mathrm{OH}, \mathrm{OR}$, halogens, etc.) with carbon monoxide in the presence of various nucleophilic reagents. At present, on the basis of the reaction of carbonylation of organic substrates, a large branch of the petrochemical industry has been created, the output of which is tens of millions of tons [5-8].

Homogeneous metal complex catalysts are more active and typically operate at low temperatures and pressures with superior regio-, enantio- and diastereoselectivities than traditional heterogeneous catalysts. In this case, the activity and selectivity of the action of the homogeneous metal complex catalyst can be optimized by varying the ligands, solvent, temperature and pressure. Such well-known disadvantages of soluble metal complex catalysts, such as the difficulty of separating them from the reaction products and their relatively low thermal stability, in some cases can be overcome by special methods, for example, heterogenization of catalysts by immobilization on inert inorganic and polymer substrates [9-12].

$\alpha$-Olefins, which are one of the large-tonnage products of the oil refining and petrochemical industries, are used for the production of surfactants, synthetic lubricants, plasticizer alcohols, fatty acids and their derivatives and monomers for the production of polymer materials [13]. One of the valuable derivatives of fatty acids obtained from terminal olefins are esters, which are widely used in practice. There are a number of wellknown methods for the synthesis of esters. The most important of these are esterification, acylation of alcohols and phenols, alcoholysis and acylation of esters, and transesterification of esters and alcoholysis of nitriles [14].

The development of homogeneous metal complex catalysis makes another way of the synthesis of esters promising - hydroalkoxycarbonylation of alkenes (alkynes) with carbon monoxide and alcohols in the presence of metal complex catalysts. The advantage of this method for the synthesis of esters is the one-step process, the availability of the starting reagents and the possibility of influencing the course of the reaction by varying the conditions of the process and the nature of the metal complex catalyst. As the latter, ICFL is often and very successfully used $[15,16]$.

The highest catalytic activity in the hydroalkoxycarbonylation reaction of olefins is exhibited by catalysts based on metal complexes of group VIII of the periodic system. The catalytic activity, stability and selectivity of the latter depend on the type of complexing agent, the composition of the coordination sphere, the conditions of the synthesis, as well as the use of external stabilizers and promoters. At the moment, the most promising are catalysts based on phosphine complexes of palladium, due to the favorable combination of donor and acceptor properties in its zero- and bivalent forms [8, 9, 14, 17-19]. Triphenylphosphine is most often used as stabilizers for catalytic systems based on palladium phosphine complexes. Its stabilizing function is associated with the stabilization of the composition of the main complex, which prevents the possible deactivation of active complexes of the catalytic reaction cycle due to the ligand exchange reaction. Various Bronsted acids are widely used as external promoters, facilitating the generation of intermediate palladium hydride complexes, which play a key role in the catalytic reaction cycle. Much less has been studied as a promoter of these reactions, Lewis acid [20-22]. The most effective are strong Bronsted acids, such as p-toluenesulfonic acid or methanesulfonic acid $\left(\mathrm{CH}_{3} \mathrm{SO}_{3} \mathrm{H}\right)$, which form conjugated weakly coordinating anions. Strongly coordinating anions reduce the rate of the kinetically important stage of the introduction of reactants (CO, olefin) into the inner sphere of the complexing metal, while weakly coordinating anions make the $\mathrm{Pd}$ center of catalytic systems more accessible, which facilitates its interaction with reactants in the catalytic cycle. 
We have carried out systematic studies of the hydroalkoxycarbonylation reaction of $\alpha$ olefins with carbon monoxide and alcohols in the presence of catalytic systems based on palladium phosphine complexes. This paper provides a brief overview of the research carried out.

\section{Experimental}

Hydroethoxycarbonylation of 1-hexene. In a steel autoclave with a capacity of $100 \mathrm{ml}$, equipped with a stirrer and a device for input and output of carbon monoxide, $0.017 \mathrm{~g} \mathrm{(5.77}$ $\left.\times 10^{-5} \mathrm{~mol}\right) \mathrm{Pd}(\mathrm{Acac})_{2}, 0.105 \mathrm{~g}\left(4.03 \times 10^{-4} \mathrm{~mol}\right) \mathrm{PPh}_{3}, 0.131 \mathrm{~g}\left(6.92 \times 10^{-4} \mathrm{~mol}\right) \mathrm{TsOH}$, $2.673 \mathrm{~g}\left(3.17 \times 10^{-2}\right)$ hexene-1 and $1.157 \mathrm{~g}\left(2.50 \times 10^{-2} \mathrm{~mol}\right)$ ethanol. The ratio of the starting reagents and components of the catalytic system $\left[\mathrm{C}_{6} \mathrm{H}_{12}\right]:\left[\mathrm{C}_{2} \mathrm{H}_{5} \mathrm{OH}\right]:\left[\mathrm{Pd}(\mathrm{Acac})_{2}\right]:\left[\mathrm{PPh}_{3}\right]:[\mathrm{TsOH}]=550: 435: 1: 7: 12$. The autoclave was sealed, flushed twice with carbon monoxide to remove air and filled with carbon monoxide to a pressure of $10 \mathrm{~atm}$, then stirring and heating were turned on. Within 0.3 hours, the temperature was raised to $100^{\circ} \mathrm{C}$ and the pressure was brought to $20 \mathrm{~atm}$, and at this temperature and pressure, the reaction mixture was stirred for 4 hours. After that, stirring and heating were stopped, the autoclave was cooled to room temperature and the reaction mixture was fractionated. $3.28 \mathrm{~g}(82.9 \%)$ of the product $\left(\mathrm{bp} 168-188^{\circ} \mathrm{C}\right)$ was obtained, which, according to GLC analysis, consisted of $70.6 \%$ ethyl enanthic acid ester and $12.3 \%$ 2-methyl caproic acid ethyl ester.

\section{Results and discussion}

The reaction of hydroethoxycarbonylation of a number of $\alpha$-olefins (hexene-1, heptene-1, octene-1, nonene-1) with carbon monoxide and alcohols in the presence of various two- and three-component systems based on the complexes $\mathrm{Pd}(\mathrm{Acac})_{2}, \mathrm{PdCl}_{2}\left(\mathrm{PPh}_{3}\right)_{2}$ and $\mathrm{Pd}\left(\mathrm{PPh}_{3}\right)_{4}$ at low pressures of carbon monoxide $(\leq 20 \mathrm{~atm})$ [23-25].

Hydroethoxycarbonylation of 1-hexene. It was found that the $\operatorname{Pd}(\mathrm{Acac})_{2}$ complex and the two-component systems $\mathrm{Pd}(\mathrm{Acac})_{2}-\mathrm{PPh}_{3}$ and $\mathrm{Pd}(\mathrm{Acac})_{2}-\mathrm{TsOH}$ in the hydroethoxycarbonylation reaction of hexene-1 at low carbon monoxide pressures $(\leq 20$ atm) do not exhibit catalytic activity. Only the three-component $\mathrm{Pd}(\mathrm{Acac})_{2}-\mathrm{PPh}_{3}-\mathrm{TsOH}$ system, which, in addition to the $\operatorname{Pd}(\text { Acac })_{2}$ complex, contains the free triphenylphosphine ligand $\mathrm{PPh}_{3}$ and p-toluenesulfonic acid as a promoter, has catalytic activity in this reaction.

The effect of different conditions of the hydroethoxycarbonylation reaction of hexene-1 in the presence of the $\mathrm{Pd}(\mathrm{Acac})_{2}-\mathrm{PPh}_{3}-\mathrm{TsOH}$ system on the yield of the reaction products was determined. It was found that the reaction proceeds with the formation of a mixture of products of linear and branched structure - ethyl esters of enanthic (EEEK) and 2-methyl caproic (EEMCA) acids. Since, due to the proximity of the boiling points of the reaction products of EEEK and EEMCC, their separation by fractional distillation fails, the ratio of the obtained isomeric products was determined by the GLC method.

It was found that the $\mathrm{Pd}(\mathrm{Acac})_{2}-\mathrm{PPh}_{3}-\mathrm{TsOH}$ system has high catalytic activity in the hydroethoxycarbonylation reaction of hexene-1: the total yield of linear and branched products, depending on the process conditions, is $18.0-82.9 \%$. The reaction proceeds with high regioselectivity with respect to the linear product: under the most optimal process conditions $\left(\left[\mathrm{Pd}(\mathrm{Acac})_{2}\right]:\left[\mathrm{PPh}_{3}\right]:[\mathrm{TsOH}]=1: 7: 12 ; \mathrm{T}=100^{\circ} \mathrm{C} ; \mathrm{Pco}=20 \mathrm{~atm} ; \tau=4\right.$ hours $)$ the ratio of linear and branched products is $[\mathrm{EEEK}]:[\mathrm{EEMKK}]=5.7: 1$.

It was found that the highest regioselectivity of the hydroethoxycarbonylation reaction of hexene- 1 is achieved when using catalytic systems based on the $\mathrm{Pd}\left(\mathrm{PPh}_{3}\right)_{4}$ complex. It was found that the $\mathrm{Pd}\left(\mathrm{PPh}_{3}\right)_{4}$ complex and the $\mathrm{Pd}\left(\mathrm{PPh}_{3}\right)_{4}-\mathrm{PPh}_{3}$ system have no catalytic 
activity in the hydroethoxycarbonylation reaction of 1-hexene at low carbon monoxide pressures $(\leq 10 \mathrm{~atm})$, while the $\mathrm{Pd}\left(\mathrm{PPh}_{3}\right)_{4}-\mathrm{TsOH}$ system has a moderate catalytic activity. The $\mathrm{Pd}\left(\mathrm{PPh}_{3}\right)_{4}$ complex is most active only in the presence of triphenylphosphine (free ligand) and p-toluenesulfonic acid as a promoter.

The most optimal ratio of the components of the catalytic system is $[\mathrm{Pd}]:\left[\mathrm{PPh}_{3}\right]:[\mathrm{TsOH}]$ $=1: 6: 12$. It is interesting to note that with a further increase in the $\mathrm{TsOH}$ content in the system to the ratio $[\mathrm{Pd}]:\left[\mathrm{PPh}_{3}\right]:[\mathrm{TsOH}]=1: 6: 13$, with a relatively small decrease in the total yield from 77.0 to $68.5 \%$, a sharp decrease in the selectivity with respect to linear product occurs. The optimum is the presence of a 6-fold excess of the $\mathrm{PPh}_{3}$ ligand. With a further increase in the $\mathrm{PPh}_{3}$ content, a gradual decrease in the total yield of products is observed. At the same time, with an increase in the $\mathrm{PPh}_{3}$ content from the ratio $[\mathrm{Pd}]:\left[\mathrm{PPh}_{3}\right]:[\mathrm{TsOH}]=$ $1: 5: 12$ to $[\mathrm{Pd}]:\left[\mathrm{PPh}_{3}\right]:[\mathrm{TsOH}]=1: 6: 12$, a sharp increase in the selectivity with respect to the linear product: the yield of a linear product increases from 57.7 to $78.6 \%$, and with a further increase in the $\mathrm{PPh}_{3}$ content it gradually decreases to $61.8 \%$.

Temperature, $\mathrm{CO}$ pressure, and reaction time also have a noticeable effect on the total yield of products and the selectivity with respect to the linear product. Temperature strongly affects the total yield and yield of the linear product and has little effect on the yield of the branched product. With an increase in temperature from 80 to $100^{\circ} \mathrm{C}$, the total product yield rises sharply from 44.6 to $77.0 \%$. At the same time, there is a strong increase in the yield of the linear product from 39.8 to $67.8 \%$, and the yield of the branched product varies only within $4.8-9.2 \%$. With a further increase in temperature, apparently due to the deactivation of the catalyst (the appearance of palladium black), a decrease in the yield is observed.

The total yield of products is relatively little influenced by the pressure of carbon monoxide. The most optimal carbon monoxide pressure is $20 \mathrm{~atm}$ (the total yield is $77.0 \%$ ). It is interesting to note that the selectivity of the reaction with respect to the linear product is significantly influenced by the pressure of carbon monoxide. The highest selectivity for a linear product is observed at a carbon monoxide pressure of $20 \mathrm{~atm}$. A decrease or increase in the pressure of carbon monoxide from a value of 20 atm causes a decrease in the selectivity of the reaction with respect to the linear product. The selectivity of the reaction with respect to the linear product is significantly influenced by the duration of the process. With an increase in the reaction time from 2 to 7 hours, the total yield of products gradually increases from 67.5 to $84.8 \%$. The curves of the dependence of the yields of linear and branched products on the reaction time differ sharply from each other. With an increase in the duration of the reaction from 2 to 5 hours, the yield of the linear product increases from 49.1 to $78.6 \%$, and with a further increase in the duration to 6 hours, it sharply decreases to $65.5 \%$ and then changes little.

Thus, it was established for the first time that the regioselectivity of the reaction with respect to the linear product is significantly influenced by the conditions of the process (the ratio of the initial reagents and the components of the catalytic system, temperature, $\mathrm{CO}$ pressure, duration). The optimal reaction conditions were found under which the highest regioselectivity of the process with respect to the linear product is achieved: $\left[\mathrm{C}_{6} \mathrm{H}_{12}\right]$ : $\left[\mathrm{C}_{2} \mathrm{H}_{5} \mathrm{OH}\right]:\left[\mathrm{Pd}\left(\mathrm{PPh}_{3}\right)_{4}\right]:\left[\mathrm{PPh}_{3}\right]:[\mathrm{TsOH}]=550: 435: 1: 6: 12 ; \mathrm{T}=100^{\circ} \mathrm{C} ; \mathrm{Pco}=20 \mathrm{~atm} ; \tau=5$ hours.

Hydroethoxycarbonylation of heptene-1, octene-1 and nonene-1. In order to determine the effect of the radical value of the starting $\alpha$-olefins on the regioselectivity of the reaction and the yield of the target products, the hydroethoxycarbonylation of heptene-1, octene-1, and nonene-1 was studied under the optimal conditions (with respect to regioselectivity) found by us for the hydroethoxycarbonylation of hexene- 1 in the presence of the $\operatorname{Pd}\left(\mathrm{PPh}_{3}\right)_{4}-$ $\mathrm{PPh}_{3}-\mathrm{TsOH}\left(\left[\mathrm{C}_{6} \mathrm{H}_{12}\right]:\left[\mathrm{C}_{2} \mathrm{H}_{5} \mathrm{OH}\right]:\left[\mathrm{Pd}\left(\mathrm{PPh}_{3}\right)_{4}\right]:\left[\mathrm{PPh}_{3}\right]:[\mathrm{TsOH}]=550: 435: 1: 6: 12 ; \mathrm{Pco}=20\right.$ atm; $\mathrm{T}=100^{\circ} \mathrm{C} ; \tau=5$ hours). The reaction also proceeds with the formation of linear and 
branched products. With an increase in the value of the radical, a slight increase in the total yield of linear and branched products is observed (from $80.7 \%$ for hexene- 1 to $82.3 \%$ for nonene-1) with a symbate slight decrease in the regioselectivity of the process with respect to the linear product.

\section{Conclusions}

High catalytic activity of three-component systems $\mathrm{PdCl}_{2}-\mathrm{PPh}_{3}-\mathrm{TsOH}, \mathrm{PdCl}_{2}\left(\mathrm{PPh}_{3}\right)_{2}-\mathrm{PPh}_{3}-$ $\mathrm{TsOH}, \quad \mathrm{Pd}(\mathrm{Acac})_{2}-\mathrm{PPh}_{3}-\mathrm{TsOH}$, and $\mathrm{Pd}\left(\mathrm{PPh}_{3}\right)_{2}-\mathrm{PPh}_{3}-\mathrm{TsOH}$ in the reaction of hydroalkoxycarbonylation of terminal olefins with carbon monoxide and alcohols has been shown. It was found that the reaction of hydroalkoxycarbonylation of normal-structure $\alpha$ olefins with carbon monoxide and alcohols proceeds with the formation of a mixture of linear and branched products.

\section{References}

1 M. Roper, Chemie Unserer Zeit 40, 126 (2006)

2 A. Behr, A.J. Vorhol, Chem. Ing. Tech. 86, 1 (2014)

3 A. Behr, P. Neubert, Applied homogeneous catalysis (Wiley-VCH, Weinheim, 2012)

4 C.A. Busacca, D.R. Fandrick, J.J. Song, C.H. Senanayake, Applications of transition metal catalysis in drug discovery and development: an industrial Perspective (John Wiley \& Sons, New York, 2012)

5 Modern carbonylation methods (Ed. Laszlo Kollar, Wiley-VCH, Weinheim, 2008)

6 X.F. Wu, X.J. Fang, L.P. Wu, R. Jackstell, H. Neumann, M. Bellar, Acc. Chem. Res. 47, 1041 (2014)

7 B.R. Sarkar, R.V. Chaudhari, Catal. Surv. Asia 9, 193 2005)

8 G. Kiss, Chem. Rev. 101, 3435 (2001)

9 A.D. Pomogajlo, Catalysis by immobilized complexes (Nauka, Moscow, 1991)

10 F. Hartli, Fixed metal complexes. A new generation of catalysts (Mir, Moscow, 1989)

11 Z.H. He, Z.S. Hou, Y.G. Zhang, T.F. Wang, Y. Dilixiati, W.M.J. Eli, Catal. Today 247, 147 (2015)

12 A.J. Pardey, J.D. Suarez, G. Gascon, M.C. Ortega, C. Longo, S.A. Moya, Cat. Lett. 126, $112(2008)$

13 D.L. Bardyk, U.L. Leffler, Petroleum chemistry [(ZAO “Olimp-Biznes”, Moscow, 2005)

14 D. Barton, W.D. Ollis, Comprehensive organic chemistry (Pergamon Press, Oxford, 1979)

15 Kh.A. Suerbaev, Metalcomplexes catalysts with phosphorcontaining ligands: aplication in organic synthesis (LAP Lambert Academic Publishing, Saarbruken, 2011)

16 E.S. Petrov, Russ. J. Phys. Chem. 62, 2858 (1988)

17 D.L. Bardyk, U.L. Leffler, Petroleum chemistry (ZAO «Olimp-Biznes», Moscow, 2005)

18 T.A. Tshabalala S.O. Ojwach, M.A. Akerman, J. Mol. Catal. A-Chem. 406, 178 (2015)

19 G. Abarca, K. Brown, S.S. Moya, J.C. Bayon, P.A. Aguirre, Catal. Lett. 145, 1396 (2015) 
20 F. Fini, M. Beltrani, R. Mancuso, B. Gabriele, C. Carfagna, Adv. Syn. Catal. 35, 177 (2015)

21 R. Purvost, J. Boulanger, B. Leger, A. Ponchel, E. Monflier, M. Ibert, A. Mortreux, T. Chenal, M. Sauthier, Chemsuschem 7, 3157 (2014)

22 B.G. Williams, M.L. Shaw, M.J. Green, C.W. Holzapfel, Angew. Chem. Int. 47, $560(2008)$

23 J. Yang, Y.Z. Yuan, Catal. Lett. 131, 643 (2009)

24 Kh.A. Suerbaev, N.Zh. Kudaibergenov, A.K. Kurmansitova, Russ. J. Gen. Chem. 86, 2124 (2016)

25 T.K. Turkbenov, Kh.A. Suerbaev, Chem. Bull. Kazakh National Univ. 3, 7 (2009) 